\title{
BURNOUT EM PROFESSORES MOCAMBICANOS DO ENSINO SUPERIOR PÚBLICO E PRIVADO
}

\section{Mussa Abacar}

Doutor em Psicologia Cognitiva, pela Universidade Federal de Pernambuco-Brasil. Docente da Universidade Pedagógica de Moçambique - Delegação de Nampula.

\section{Laurentino Tarcísio}

Mestre em Administração e Gestão Escolar, pela Universidade Pedagógica de Moçambique. Docente da Universidade Pedagógica - Delegação de Nampula.

\section{Gildo Aliante}

Mestrando em Psicologia Social e Institucional pela Universidade Federal do Rio Grande do Sul (UFRGS), Brasil. Bolsista de Mestrado do CNPq.

E-mail: aliantegildo@yahoo.com.br
RESUMO: Este estudo objetivou avaliar a incidência da síndrome de burnout em professores de instituições de ensino superior da rede pública e privada na cidade de Nampula, Moçambique, para verificar suas possíveis associações com variáveis sociodemográficas. Tratase de um estudo descritivo e exploratório, de cunho quantitativo. Participaram 240 professores, sendo 120 de universidades públicas e igual número das privadas. Os dados foram coletados por meio de questionário sociodemográfico e do inventário Maslach Burnout Inventory (MBI) e, analisados com apoio do Software Statistical Package for Social Sciences (SPSS). A análise dos níveis de confiabilidade do MBI revelou boas propriedades psicométricas do instrumento, com coeficientes alpha de Cronbach igual a 0,8; 0,8 e 0,7 respectivamente para as subescalas exaustão emocional, despersonalização e realização pessoal. Os professores investigados apresentam nível de despersonalização relativamente maior, bem como baixa realização no trabalho, com médias de 4.17 e 1.28 respectivamente. Professores da rede pública demonstraram médias elevadas em exaustão emocional (4.86) e despersonalização (3.81), revelando maior tendência de sofrer da síndrome de burnout, em comparação com os seus congêneres de instituições de ensino superior privadas. Os níveis de burnout diferem entre os professores, sendo que professores mais velhos, mais experientes, do ensino público, contratados e do sexo feminino revelaram tendência à doença, nos níveis de exaustão emocional e despersonalização. Estes resultados evidenciam a necessidade de as instituições de ensino superior estabelecerem campanhas de sensibilização aos professores no sentido de diminuir ou eliminar a incidência da síndrome de burnout nesse grupo profissional.

PALAVRAS-CHAVE: Stress; Burnout; Professores; Ensino superior.

\section{BURNOUT SYNDROME IN PUBLIC AND PRIVATE HIGHER EDUCATION PROFESSORS FROM MOZAMBIQUE}

\begin{abstract}
The occurrence of the burnout syndrome in professor of higher education institutions, both government-run and private, in Nampula, Mozambique, is analyzed to verify its possible associations with social and demographic variables. The descriptive, exploratory and quantitative study comprised 240 professors, divided exactly between public and private institutions. Data were collected by a socio-demographic questionnaire and by Maslach Burnout Inventory (MBI) and analyzed with Software Statistical Package for Social Sciences (SPSS). The analysis of MBI's reliability levels revealed good psychometric factors, with Cronbach's alpha coefficients at $0.8,0.8$ and 0.7 , respectively, for the sub-scales emotional exhaustion, depersonification and personal fulfillment. The professors showed a relatively deeper depersonalization level and low fulfillment in their job,
\end{abstract}


with averages 4.17 and 1.28, respectively. Professors from government-run institutions averaged high emotional exhaustion (4.86) and depersonalization (3.81), with a greater trend towards the burnout syndrome, when compared to colleagues in private schools. Burnout levels differed among professors: older and more experienced male professors from public schools and female professors revealed emotional exhaustion and depersonalization trends. Results show that higher education institutions should establish campaigns to decrease or eliminate the occurrence of the burnout syndrome in this professional group.

KEY WORDS: Stress; Burnout; Professors; Higher education.

\section{INTRODUÇÃO}

O termo burnout refere-se ao esgotamento da capacidade de trabalhadores para manter um envolvimento intenso com impacto significativo no trabalho, ou seja, que se chegou ao limite do esforço, e que, pel falta de energia, não há mais condições físicas nem mentais para trabalhar (BENETTI et al., 2009). Maslach e Jackson (1981) consideram que o burnout descreve um estresse laboral que conduz a um tratamento frio e indiferente com o cliente caracterizado por três componentes: exaustão emocional, despersonalização e baixo sentimento de realização pessoal no trabalho.

A exaustão emocional caracteriza-se pela sensação de esgotamento emocional e físico. Trata-se da constatação de que não se dispõe mais de nenhum resquício de energia para levar adiante as atividades laborais. O cotidiano no trabalho passa a ser penoso e doloroso. A despersonalização é marcada pelo desenvolvimento de atitudes e sentimentos negativos e de cinismo em relação a clientes e usuários. É caracterizada pela ausência de sensibilidade, manifestada pelo endurecimento afetivo, "coisificação" das relações interpessoais, levando o indivíduo a ter um contato frio e impessoal com os usuários de seus serviços, passando a ter atitudes de ironia em relação às pessoas, mostrandose indiferente ao que possa acontecer aos demais; o profissional passa a tratar os clientes, colegas e a organização como objetos. Por fim, a baixa realização no trabalbo é sentimento de insatisfação com as atividades laborais que vêm realizando e com seu desenvolvimento emocional, sentimento de insuficiência, de baixa autoestima, de fracasso profissional e de desmotivação. Portanto, o trabalhador sente-se infeliz consigo mesmo e insatisfeito com suas realizações no trabalho, sentindo algumas vezes o desejo de abandonar o emprego, caracterizando-se por uma autoavaliação negativa.

Schaufeli e Buunk (2003) elaboraram um agrupamento dos sinais e sintomas da síndrome de burnout da seguinte maneira: i) manifestações afetivas (tristeza, depressão, ansiedade, agressividade e irritabilidade); ii) manifestações cognitivas (sentimentos de desespero, desamparo, fraqueza e impotência, sensação de fracasso e insuficiência, baixa autoestima relacionada ao trabalho, rigidez de pensamentos, isolamento, debilidade de habilidades cognitiva como memória e atenção, negativismo, pessimismo, redução de empatia, estereótipos, desconfiança e uma atitude extremamente crítica em relação aos gestores, colegas e supervisores); iii) manifestações físicas (gripe frequente, queixas somáticas, níveis mais altos de cortisol e colesterol e doenças cardíacas coronarianas); iv) manifestações comportamentais (abuso de substâncias, o absentismo, intenção de abandono da profissão ou turnover e fraco desempenho no trabalho) e v) manifestações motivacionais (perda de zelo, entusiasmo, interesse e de idealismo; indiferença, decepção e resignação, conflitos interpessoais e retirada física e mental no trabalho).

As causas da síndrome de burnout são diversas. No entanto, recentemente, trabalhos sobre o burnout começaram a desenvolver novos referenciais teóricos que integram de forma mais explícita os fatores individuais e situacionais, ao invés de tratá-los em separado. Nessa perspectiva, Maslach e Leiter (1999) formularam um modelo que enfoca o grau de desajuste entre a pessoa e os seis domínios do ambiente do trabalho como: a) carga de trabalbo (as exigências que o trabalho impõe sobre o funcionário), b) controle (capacidade de percepção dos trabalhadores para influenciar as decisões que afetam o seu trabalho, para o exercício de autonomia profissional e para ter acesso aos recursos necessários para fazer um trabalho eficaz), c) recompensa (extensão em que as recompensas monetárias, sociais e intrínsecas são consistentes com as expectativas do trabalhador), d) 
comunidade (qualidade da interação social no trabalho, incluindo questões de conflitos interpessoais, apoio social, proximidade e a capacidade de trabalhar em equipa), e) justiça (medida que as decisões no trabalho são percebidas como sendo justas e as pessoas são tratadas com respeito) e f) valores (estão vinculados ao poder cognitivo-emocional das metas de trabalho e expetactivas). Assim, quanto maior for a incongruência percebida entre a pessoa e esses seis domínios, maior a probabilidade da ocorrência do burnout e, inversamente, quanto maior a congruência percebida, maior a probabilidade de engajamento no trabalho (MASLACH; SCHAUFELI; LEITER, 2001).

O burnout é assim resultado da incongruência percebida entre a pessoa e os seis domínios da vida profissional anteriormente apresentados. Assim, ele surge da incompatibilidade crônica entre a pessoa e seu ambiente de trabalho, em termos de algumas ou de todas as seis áreas ou domínios, constituindo os principais antecedentes organizacionais de burnout (MASLACH et al., 2001).

Apesar de o burnout atingir trabalhadores de diferentes países do mundo, o que leva a ser considerado como um problema de carácter epidêmico mundial (GILMONTE, 2008) e existir uma série de estudos empíricos sobre a síndrome em professores, pouca sensibilização a respeito do assunto e pesquisa tem sido realizada na África (AMIMO, 2012). No contexto moçambicano, existe uma carência de estudos sobre a temática, especialmente os centrados em professores do ensino superior. No entanto, a precariedade das condições de trabalho dos professores moçambicanos, caracterizada por falta de controle do trabalho; inadequadas condições de trabalho; recompensas insuficientes a seu favor; sobrecarga de trabalho; injustiças no local de trabalho; conflito de valores; dedicação exagerada à atividade docente, desejo de ser o melhor e sempre demonstrar alto grau de desempenho, ausência de suporte social, falta de reconhecimento profissional, transforma em obstinação e compulsão originando problemas de ordem psicológica, forte desgaste físico, gerando fadiga e exaustão.

Por meio de uma revisão da literatura existente sobre as causas de burnout entre professores do ensino médio e fundamental e estratégias de prevenção, Yong e
Yue (2007) apontam cinco razões para a ocorrência do burnout do professor na China, que têm sido encontradas por pesquisadores da área em diferentes países: 1) fatores do aluno: a) indisciplina dos alunos, b) falta de motivação para os estudos e c) pressão em entrar no nível seguinte de educação; 2) fatores de trabalbo: a) salários excessivamente baixos, b) falta de autoridade e status social e, c) classes numerosas; 3) fatores organizacionais da escola: a) tensas relações interpessoais, b) sobrecarga de trabalho e demais responsabilidades não educativas, c) falta de apoio e de reconhecimento da liderança e dos colegas, d) pressão de tempo, e) ineficácia das reformas educacionais, confusão e conflito de papéis, f) mau clima escolar e de classe, g) pressão dos supervisores e inspetores e, h) más condições de trabalho; 4) fatores pessoais: a) altas expectativas pessoais, b) incapacidade e c) exigências de trabalho; 5) fatores extraescolares: a) pressão da sociedade e dos pais e b) redução de pessoal.

A pesquisa global do fenômeno de burnout em professores revela que é a epidemia que mais tem contribuído para o desgaste da maioria dos professores (AMIMO, 2012). Normalmente, o burnout do professor começa com uma sensação de estar emocionalmente sobrecarregado e drenado pelo contato intenso com alunos, pais e colegas (exaustão emocional); em seguida, pode levar o professor a manifestar atitudes negativas e respostas cínicas para com os alunos (despersonalização) e, finalmente, um declínio no senso de competência, o que resulta na avaliação negativa do seu desempenho e na redução da realização no trabalho (PLATSIDOU, 2010).

As pesquisas sobre o burnout são escassas em Moçambique, especialmente na classe docente. No entanto, estudos realizados em diversos países demonstram a prevalência da síndrome em professores do ensino superior. Suda, Coelho, Bertaci e Santos (2011) encontraram correlação positiva entre nível geral de saúde precário de professores brasileiros e a exaustão emocional. Em um estudo com professores colombianos, Botero e Romero (2011) revelaram que a prevalência dos casos prováveis de burnout foi de 19,1\%, e 49,4\% dos professores estavam em risco de sofrer a síndrome. Nesse estudo, os professores revelaram elevados níveis de exaustão emocional e despersonalização $(32,6 \%$ e $30,6 \%)$ e baixo nível de realização profissional $(38,2 \%)$. 
De forma idêntica, a partir de uma amostra com professores universitários brasileiros, Garcia e Benevides-Pereira (2003) evidenciaram que, cerca de $1 / 3$ revelavam elevada exaustão emocional, bem como $1 / 5$ de despersonalização e reduzida realização pessoal no trabalho. Igualmente, em sua pesquisa com professores universitários brasileiros, Carneiro (2011) revelou que grande parte da amostra $(63,1 \%)$ encontravase em processo de instalação da síndrome de burnout e 20,23\% já estavam com a síndrome instalada. A partir de uma amostra de professores portugueses do ensino superior, Martins (2008) também evidenciou que embora os participantes não tenham revelado sofrer a síndrome de burnout, encontravam-se emocionalmente exaustos.

Baseando-se no referencial teórico apresentado, o problema central da investigação traduz-se na seguinte questão: Qual a incidência da síndrome de burnout em professores de instituições do ensino superior público e privadas da cidade de Nampula? O objetivo geral do estudo foi o de avaliar a incidência da síndrome de burnout em docentes de instituições de ensino superior público e privada locados na cidade de Nampula, verificando suas possíveis associações com variáveis sociodemográficas.

Em função do objetivo da pesquisa foram formuladas as seguintes hipóteses: H1) pela insegurança no emprego, espera-se a existência de maior pontuação em burnout em professores de universidades privadas e, H2) o nível de burnout difere entre os professores em função das variáveis: sexo, grau de escolaridade, tipo de ensino, vínculo institucional, nível de experiência, estado civil e número de filhos.

\section{METODOLOGIA}

\subsection{TIPO DE PESQUISA}

A presente pesquisa é de natureza quantitativa, pois recorreu aos instrumentos de mensuração e técnicas estatísticas para a coleta, classificação e análise dos dados. Trata-se de um estudo descritivo e exploratório. Os dados foram coletados por meio de questionário sociodemográfico e questionário MBI-ED (Maslach Burnout Inventory-Educatory Survey).

\subsection{PROCEDIMENTOS}

Esta pesquisa foi desenvolvida em seis instituições de ensino superior locados na cidade de Nampula nomeadamente: Universidade Pedagógica Delegação de Nampula, Academia Militar, Universidade Católica de Moçambique, Universidade Mussa Bim Bique, A Politécnica e Universidade Lúrio. A coleta de dados foi realizada nos meses de maio e junho de 2016. Primeiramente, foram efetuados contatos com os gestores das instituições envolvidas no estudo tendo o mesmo sido formalizado por meio de carta que apresentava o objetivo da investigação e solicitava autorização para a sua realização. Após a autorização, foram contatados os professores e informados sobre os objetivos do estudo $\mathrm{e}$, posteriormente, responderam individualmente $\mathrm{o}$ instrumento de pesquisa, mediante instruções dadas pelo segundo autor do trabalho. O projeto foi aprovado pela Direcção de Pós-graduação, Pesquisa e Extensão da Universidade Pedagógica de Nampula, parecer $n^{0} 02 /$ DPPE/UPN/2016.

\subsection{INSTRUMENTOS DE RECOLHA DE DADOS}

Foi utilizado um questionário constituído por duas partes: dados sociodemográficos (elaborado pelos autores do trabalho) e o Maslach Burnout Inventary Educador Survey (MBI-ES) de Maslach e Jackson (1981), instrumento utilizado para coletar dados relacionados com dimensões de burnout: exaustão emocional, despersonalização e baixa realização profissional.

A escala inicial do MBI-GS (Maslach Burnout Inventary-General Survey), desenvolvida por Maslach $\mathrm{e}$ Jackson (1981) contém as seguintes subescalas e itens: exaustão emocional (9 itens), despersonalização (5 itens), realização pessoal (8 itens) e envolvimento com pessoas ( 1 fator fraco de 3 itens com eigenvolue inferior a 1,0 e minuto relacionado com a elevada exaustão emocional). Investigações posteriores excluíram o último fator tendo ficado apenas com os três primeiros com um total de 22 itens (AGUAYO et al., 2011; ALUJA; BLANC; GARCIA, 2005; GODDARD; O'BRIEN; GODDARD, 2006).

A modificação da escala original do MBI com a escala MBI-Educator Survey, aplicada neste estudo, foi substituição do termo "Cliente" pelo termo "aluno". Os participantes fornecem as suas respostas a partir de uma escala denominada Likert de 6 pontos, sendo 0 (nunca), 
1 (algumas vezes por ano), 2 ( 1 vez por mês) 3 (algumas vezes por mês), 4 ( 1 vez por semana) 5 (algumas vezes por semana) e 6 (todos os dias). Ele identifica índices de burnout de acordo com os escores de cada dimensão; os altos escores em exaustão emocional e despersonalização e baixos escores em realização profissional (essa subescala é inversa) indicam alto nível de burnout (MASLACH; JACKSON, 1986).

Com base nesse instrumento, todos os participantes foram convidados a avaliar o que tinha sentido acerca do seu trabalho docente assinalando a alternativa que melhor correspondia ao próprio caso. A aplicação do instrumento em professores tem revelado boas propriedades psicométricas.

\subsection{PERFIL DOS PARTICIPANTES}

A amostra foi constituída por 240 professores do ensino superior, sendo 120 do ensino público e igual número do ensino privado, sendo 125 mulheres e 115 homens. Em termos de faixa etária, 62 professores situamse entre os 27 a 35 anos; 80 entre 36 a 44 anos; 73 entre 45 a 53 anos e 25 entre 54 a 63. Com relação ao estado civil do total dos professores, 100 solteiros, 118 casados, 12 separados e dez viúvos. Em relação ao número de filhos, apenas três participantes declararam não ter filhos.

O nível de escolaridade dos participantes varia entre licenciatura e doutoramento, sendo que 70 professores participantes possuem o nível de licenciados,
160 o nível mestres e dez habilitados com o nível de doutorado. Os anos de experiência dos professores variam de um a 32 anos. Por fim, 133 professores são efetivos e 107 contratados.

\subsection{TÉCNICA DE ANÁLISE DE DADOS}

Os dados da pesquisa foram tabulados $\mathrm{e}$ analisados, considerando os objetivos da mesma e recorrendo a abordagem indutiva. Para tal, foi utilizado o software Statistical Package for the Social Sciences (SPSS), versão 2013.

\section{RESULTADOS E DISCUSSÃO}

Nesta parte são analisados e discutidos os resultados obtidos neste estudo. Os resultados são apresentados em forma de tabelas, acompanhadas por sua descrição e discussão.

\subsection{CONFIABILIDADE INTERNA DA ESCALA MBI}

Para avaliar a confiabilidade do MBI foi calculado o coeficiente alpha do instrumento. Na Tabela 1 são apresentados os valores de medida de confiabilidade de alpha de Cronbach das três dimensões de burnout e o alpha geral do questionário Maslach Burnout Inventory.

Tabela 1. Confiabilidade interna da escala MBI

\begin{tabular}{|c|c|c|c|c|c|c|c|}
\hline \multicolumn{6}{|c|}{ Dimensões de burnout } & \multirow{2}{*}{\multicolumn{2}{|c|}{ Geral }} \\
\hline \multicolumn{2}{|c|}{ Exaustão Emocional } & \multicolumn{2}{|c|}{ Despersonalização } & \multicolumn{2}{|c|}{ Baixa Realização profissional } & & \\
\hline $\begin{array}{l}\text { Alpha de } \\
\text { Cronbach }\end{array}$ & $\mathrm{N}^{\mathrm{o}}$ de itens & $\begin{array}{l}\text { Alpha de } \\
\text { Cronbach }\end{array}$ & $\mathrm{N}^{\mathrm{o}}$ de itens & $\begin{array}{l}\text { Alpha de } \\
\text { Cronbach }\end{array}$ & $\mathrm{N}^{\mathrm{o}}$ de itens & $\begin{array}{l}\text { Alpha de } \\
\text { Cronbach }\end{array}$ & $\mathrm{N}^{\mathrm{o}}$ de itens \\
\hline 0.817 & 9 & 0.801 & 5 & 0.701 & 8 & 0.856 & 22 \\
\hline
\end{tabular}

Em termos de estatística descritiva, os resultados obtidos a partir da amostra do presente estudo revelaram que todas as dimensões do MBI apresentaram boa consistência interna. A dimensão exaustão emocional apresentou o alpha de Cronbach 0,817, a de despersonalização 0,801 e realização profissional de 0,756. Analisando a consistência interna das três dimensões, exaustão emocional, despersonalização e realização pessoal, mostra uma boa consistência interna, pois apresenta um valor de alpha de Cronbach de 0,856 $(\alpha=0,856)$. 
Esses resultados corroboram com os encontrados em outros estudos. Aguayo et al. (2011), por exemplo, analisaram 45 estudos tendo identificados 51 valores de coeficientes alfa de Cronbach com confiabilidade média de $0,88,0,71$ e 0,78 , sucessivamente para as dimensões exaustão emocional, despersonalização e realização pessoal. Outra revisão envolvendo 221 estudos, realizada por Wheeler, Vassar, Worley e Barnes (2011), dos quais 84 forneciam coeficientes alfa, revelou médias estimadas desse coeficiente para todas as subescalas do MBI em torno de 0,70 a 0,80 .

\subsection{MÉDIA DAS DIMENSÕES DE BURNOUT}

Na Tabela 2 são apresentadas as médias e o desvio-padrão das três dimensões, onde são ilustradas as tendências dos resultados desta pesquisa, ou seja, o nível de burnout dos professores pesquisados. A média e o desvio-padrão das dimensões do MBI nas amostras estudadas pode-se observar que houve diferença significativa entre as dimensões. A dimensão exaustão emocional apresenta uma média de $2.16+1.121$, a dimensão despersonalização média de $4.17+0,967$ e, por fim, a dimensão realização profissional valor de média de $1.286+0.797$. Estes resultados indicam que os professores pesquisados apresentam maior nível de despersonalização e baixo nível de realização profissional.

Tabela 2. Médias das dimensões de burnout

\begin{tabular}{l|l|l}
\hline Dimensões de burnout & Média & Desvio-padrão \\
\hline Exaustão emocional & 2,157 & 1,121 \\
\hline Despersonalização & 4,170 & 0,967 \\
\hline Realização Pessoal & 1,286 & 0,797 \\
\hline
\end{tabular}

Resultados similares foram encontrados por Botero e Romero (2011) num estudo com professores colombianos do ensino superior. Os professores estudados por esses autores revelaram elevados níveis de exaustão emocional e despersonalização (32,6\% e 30,6\%) e baixo nível de realização profissional (38,2\%). Também Martins (2008) identificou que professores portugueses do ensino superior encontravam-se emocionalmente exaustos.

Há indicativos de síndrome de burnout quando são obtidos escores elevados nas duas dimensões de exaustão emocional e despersonalização e baixo escore na realização profissional (MASLACH; JACKSON, 1981). Neste estudo, merece atenção as pontuações encontradas na análise realizada do MBI, em virtude de apresentar nível elevado em despersonalização e baixo nível em realização pessoal, pois demonstra tendência ao esgotamento profissional dos professores estudados.

\subsection{DIMENSÕES DE BURNOUT E VARIÁVEIS SOCIODE- MOGRÁFICAS}

Com o intuito de avaliar a relação entre as dimensões da síndrome de burnout com os dados sociodemográficos dos docentes, inicialmente optouse em averiguar se haveria diferença da incidência da doença em relação ao gênero, faixa etária, estado civil, número de filhos, nível de escolaridade, número de anos na docência, tipo de ensino e vínculo laboral. Foi utilizado o índice de correlação de SPEARMAN, tendo se obtido os resultados da Tabela 3 .

Tabela 3. Correlação entre as dimensões burnout e variáveis idade, $n^{\circ}$ de filhos, nível de escolaridade e anos na docência

\begin{tabular}{|c|c|c|c|c|c|c|c|c|}
\hline & & DP & $\mathrm{RP}$ & $\mathrm{EE}$ & Idade & $\begin{array}{l}\mathrm{N}^{\circ} \mathrm{de} \\
\text { filhos }\end{array}$ & $\begin{array}{l}\text { Nível de } \\
\text { escolaridade }\end{array}$ & Experiência \\
\hline $\begin{array}{l}\text { Corr } \\
\mathrm{EE}\end{array}$ & $\begin{array}{l}\text { Sig. } \\
\mathrm{N}\end{array}$ & $\begin{array}{l}.174 * * \\
.007 \\
240 \\
\end{array}$ & $\begin{array}{l}.278^{* *} \\
.000 \\
240 \\
\end{array}$ & $\begin{array}{l}1.000 \\
240 \\
\end{array}$ & $\begin{array}{l}.150 * \\
.020 \\
240 \\
\end{array}$ & $\begin{array}{l}.070 \\
.278 \\
240 \\
\end{array}$ & $\begin{array}{l}.123 \\
.056 \\
240 \\
\end{array}$ & $\begin{array}{l}236 * * \\
.000 \\
240 \\
\end{array}$ \\
\hline DP & $\begin{array}{l}\text { Corr } \\
\text { Sig. } \\
\mathrm{N}\end{array}$ & $\begin{array}{l}1.000 \\
240\end{array}$ & $\begin{array}{l}.178^{* *} \\
.006 \\
240\end{array}$ & $\begin{array}{l}.174^{* *} \\
.007 \\
240\end{array}$ & $\begin{array}{l}.155^{*} \\
.016 \\
240\end{array}$ & $\begin{array}{l}.131 * \\
.042 \\
240\end{array}$ & $\begin{array}{l}.073 \\
.262 \\
240\end{array}$ & $\begin{array}{l}.147^{*} \\
.023 \\
240\end{array}$ \\
\hline $\begin{array}{l}\text { Corr } \\
\text { RP }\end{array}$ & $\begin{array}{l}\text { Sig. } \\
\mathrm{N}\end{array}$ & $\begin{array}{l}.178^{* * *} \\
.006 \\
240\end{array}$ & $\begin{array}{l}1.000 \\
240\end{array}$ & $\begin{array}{l}.278^{* *} \\
.000 \\
240\end{array}$ & $\begin{array}{l}.043 \\
.509 \\
240\end{array}$ & $\begin{array}{l}.095 \\
.141 \\
240\end{array}$ & $\begin{array}{l}.011 \\
.863 \\
240\end{array}$ & $\begin{array}{l}.102 \\
.115 \\
240\end{array}$ \\
\hline
\end{tabular}

** Correlações significativas ao nível de 0,01; * Correlações significativas em nível de 0,05

EE (Exaustão emocional); DP (Despersonalização); RP (Realização profissional) 
Conforme a Tabela 03, o teste mostra que a correlação entre a dimensão exaustão emocional e idade é de 0.15 associada a um nível de significância de 0.020 menor que 0.05 . Portanto, a correlação entre essas duas variáveis é significativa, ou seja, na medida em que a idade aumenta a exaustão emocional também aumenta, pois a correlação é positiva. A variável idade também apresentou correlação estatisticamente significativa e positiva com a despersonalização, revelando que quanto maior for a idade, maior é o nível de despersonalização.

Estes resultados não corroboram com o estudo de Benevides-Pereira (2002) que demonstrou que pessoas mais jovens apresentam maior probabilidade à síndrome de burnout, sendo isto atribuído a vários fatores como pouca experiência que acarreta insegurança ou choque diante da realidade do trabalho, o reconhecimento acadêmico, o desenvolvimento de pesquisas e a publicação científica. Na verdade, Costa e Silva (2012) revelaram que professores brasileiros com idade compreendida entre 20 e 30 anos mostram alto índice de exaustão emocional; entre 30 e 40 anos tiveram uma baixa média em exaustão emocional e despersonalização e um valor médio de realização profissional, e aqueles com 40 a 50 anos de idade foi o grupo mais preocupante, por apresentar o limite em todos os itens que caracterizam a síndrome de burnout.

Neste estudo, a correlação entre as três dimensões de burnout e a titulação acadêmica não demonstrou qualquer associação estatisticamente significativa. Estes não corroboram com o estudo realizado por Maslach et al. (2001) em que demonstraram que, geralmente, professores com maior nível acadêmico apresentem níveis mais altos de burnout em relação a professores com menor titulação. A educação pode influenciar a realização pessoal, o que significa o nível educacional poder ser interpretado como um fator de proteção contra o burnout, assim como, o aumento da idade (MILIĆEVIĆ-KALAŠIĆ, 2013). Ainda assim, segundo Maslach et al. (2001), o nível de escolaridade elevado se encontra relacionado a maiores responsabilidades $\mathrm{e}$ assim ao stress.

A variável anos de experiência na docência apresentou correlação positiva com exaustão emocional e despersonalização. À medida que os professores vão tendo mais anos de serviço, também aumenta o nível de exaustão emocional e de despersonalização. Enquanto a realização pessoal não apresentou nenhuma correlação estatisticamente significativa. Goddard et al. (2006) descobriram que professores iniciantes relatavam aumentos significativos da síndrome de burnout. Por sua vez, Betoret e Artiga (2010) constataram que à medida que professores espanhóis ganhavam mais experiência, revelavam autopercepção de menor eficácia no trabalho. Outros estudos (e.g., OZDEMIR, 2007) mostram que a síndrome de burnout aparece no início e no final da carreira dos professores.

Em relação ao número de filhos, o teste de correlação mostra a correlação 0.9 associada com o nível de significância de 0.1 menor que 0.05 . Nesse caso, a correlação entre as variáveis número de filhos e realização pessoal é estatisticamente significativa, mais positiva, pode-se dizer que os professores com filhos envolvidos nesta pesquisa tendem a manifestar a despersonalização. A semelhança do estudo de Abacar (2015) sobre o burnout em professores moçambicanos e brasileiros, a mesma variável (número de filhos) não demonstrou qualquer correlação estatisticamente significativa com a dimensão realização profissional e exaustão emocional. Estes achados, não estão de acordo com os esperados teórica e empiricamente, pós a paternidade equilibra o profissional, permitindo melhores estratégias de enfrentamento das situações conflituosas e dos agentes geradores de estresse ocupacional (MASLACH et al., 2001).

Na sequência das análises, foram correlacionadas três dimensões de burnout com as variáveis, sexo, estado civil, tipo de ensino e vínculo laboral utilizando o teste de QUI-QUADRADO (Tabela 04). 
Tabela 4. Correlações das dimensões de burnout com as variáveis sexo, estado civil, tipo de ensino e vínculo laboral

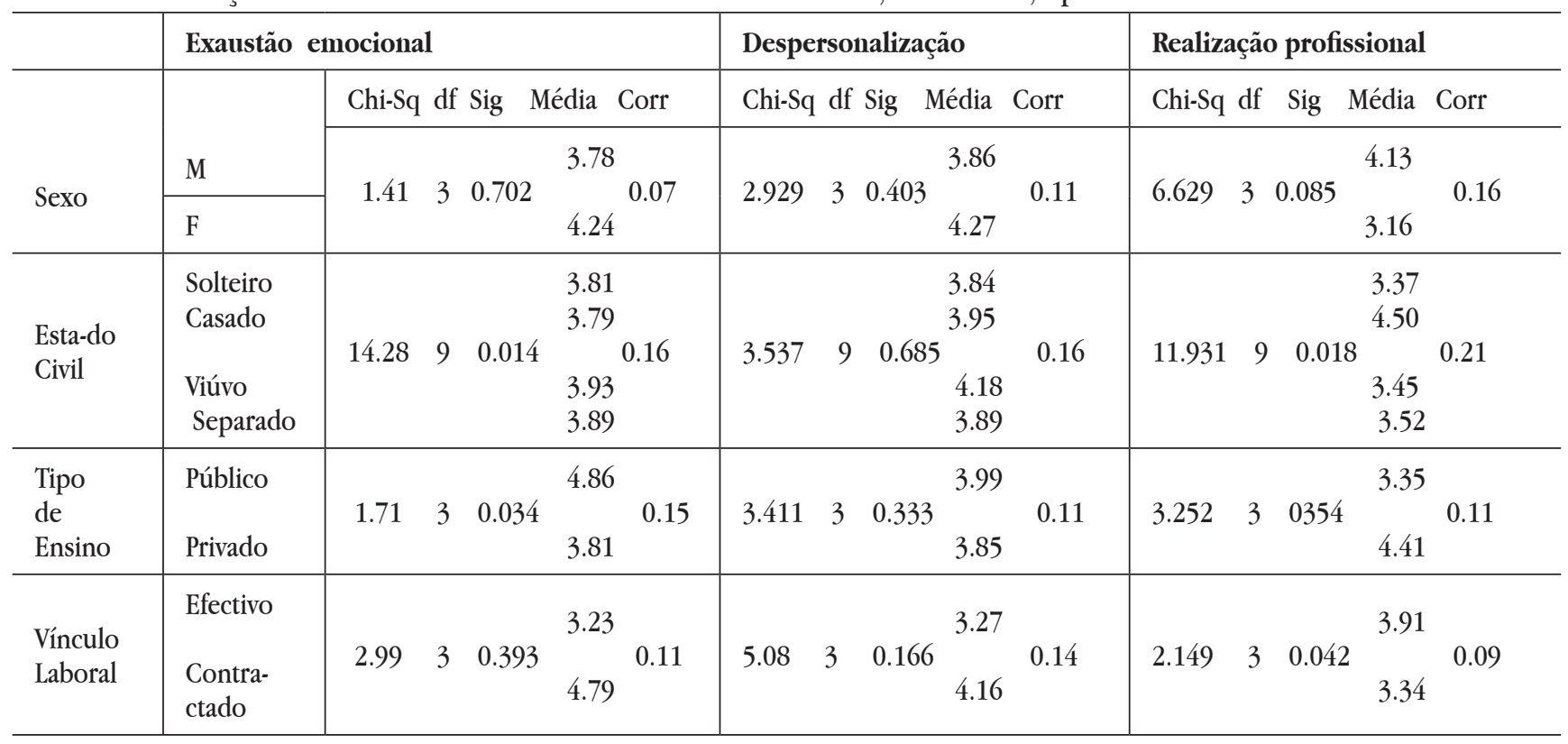

As variáveis sexo e exaustão emocional apresentaram correlação de 0.077 , com nível de significância de 0.702 maior que 0.05 . Embora a correlação não seja significativa, os resultados indicam que a média 3.84 das mulheres é ligeiramente alta em relação aos homens, cuja média é de 4.24. Em relação à despersonalização a correlação é de 0.11 e nível de significância de é 0.403 , sendo que a média nas mulheres é 4.27 e nos homens 3.86 com correlação estatisticamente significativa. Sobre a realização profissional o nível de significância é de $0.085,3.16$ média das mulheres e nos homens 4.13, a correlação é de 0.156 .

Conforme os resultados apresentados, os professores do sexo feminino apresentam pontuação média maior nas dimensões exaustão emocional e despersonalização, caracterizando maior tendência a apresentar a síndrome de burnout. Ainda assim, Maslach et al. (2001) afirmam que se verifica uma tendência para as mulheres evidenciarem maior pontuação em exaustão emocional do que os homens, enquanto os homens tendem a ter pontuação mais elevada em despersonalização do que as mulheres. Farber (1991) considera que os professores do sexo feminino são mais vulneráveis porque são menos flexíveis que os do sexo masculino, embora, sejam mais abertas para lidar com as várias pressões presentes na profissão de ensino. Estudo de Garcia e Benevides-Pereira (2003) revelaram média elevada em professores brasileiros do gênero feminino.
Averiguou-se que existem diferenças estatisticamente significativas entre os vários grupos que constituem a variável estado civil, para as três dimensões do burnout. Os viúvos apresentam a média mais alta, 3.93 na exaustão emocional e 4.18 na despersonalização em relação a outros grupos. Na realização pessoal, os casados tem média alta de 4.50. Nas três dimensões as correlações são estatisticamente significativas e positivas, sendo na exaustão emocional de 0.16 , despersonalização 0.163 e na realização profissional 0.018 .

Tal como este estudo, pesquisas revelam que trabalhadores solteiros apresentam maiores níveis de burnout, comparativamente aos indivíduos casados (ABACAR, 2015; AYDEMIR; ICELLI, 2013; MASLACH; JACKSON, 1985). Geralmente, atribui-se ao casamento ou ao fato de ter um relacionamento afetivo estável, menor propensão ao burnout, enquanto os maiores valores na síndrome têm sido apontado nos solteiros, viúvos e divorciados (MASLACH et al., 2001). Outra explicação de o porquê as pessoas com famílias (casadas) são menos vulneráveis ao burnout, segundo Aydemir e Icelli (2013), reside no fato destas tenderem a ser mais velhas, mais estáveis e psicologicamente maduras (ter compreensão sólida e precisa da realidade social, e ser mais construtiva e adaptável na natureza) e o envolvimento com o cônjuge e filhos torna-lhes mais experientes em lidar com problemas interpessoais e conflitos emocionais. 
A variável tipo de ensino demonstrou diferenças estatisticamente significativas com as três dimensões de burnout. Na dimensão exaustão emocional, a correlação é de 0.15 , na despersonalização é de 0.11 e realização profissional é de 0.094. Os professores das instituições públicas têm média alta na dimensão exaustão emocional (4.86) e despersonalização (3.81). Por fim, os professores do ensino privado obtiveram média de 4.41 em realização profissional. Esses achados revelam que os professores das instituições do ensino público tendem a manifestar exaustão emocional, despersonalização e menor realização profissional no trabalho, em comparação com os seus congêneres do ensino privado.

Em relação à variável vínculo laboral, o teste de correlação mostrou nível de significância de 0.393 na dimensão exaustão emocional, 0.166 na despersonalização e 0.042 na realização profissional. Nesse caso, a correlação é estatisticamente significativa e positiva visto que na exaustão emocional é de 0.111 , despersonalização é de 0.144 e realização profissional é de 0.094 . Na dimensão exaustão emocional a média é de 4.79 para os professores contratados e 3.21 para os efetivos; na despersonalização a média é de 4.16 para os contratados e 3.27 para os efetivos e; por fim, realização profissional a média é de 3.92 para os professores efetivos e de média de 3.34 para os contratados.

Os resultados encontrados permitem assinalar que professores contratados tendem a manifestar maior nível de exaustão emocional e despersonalização e menor nível de realização profissional em comparação com os efetivos, o que pode ser explicado pela incerteza em relação o futuro profissional. Além disso, professores sem vínculo definitivo com o Estado têm mais chances de abandonar a profissão docente em busca de melhores oportunidades de emprego.

\section{CONCLUSÃO}

Este estudo procurou avaliar a incidência da síndrome de burnout em professores de instituições do ensino universitário público e privado na cidade de Nampula. Os resultados da pesquisa permitem concluir que, contariamente o previsto na $\mathrm{H} 1$, a qual aventava a existência de maior pontuação em burnout em professores de universidades privadas, os professores do ensino público é o grupo que apresentou maiores pontuações em burnout. E como previsto, na H2, o burnout difere entre os professores em função das variáveis sexo, grau de escolaridade, tipo de ensino, vínculo institucional, nível de experiência, estado civil e número de filhos, corroborando essa hipótese. Para sustentar esta posição, as análises realizadas da relação dessas variáveis com as dimensõesdeburnout evidenciaram diferentes resultados. De forma geral, os participantes deste estudo revelaram maior despersonalização e baixa realização pessoal, sendo níveis preocupantes da doença, já que evidencia os professores estarem numa fase de desenvolvimento de burnout. Isso remete à implementação de medidas de prevenção primária e secundária por forma a reduzir, ou de preferência, eliminar a síndrome de burnout nos professores estudados. Igualmente, seria desejável a existência de serviços de aconselhamento psicológico no contexto de trabalho dos professores, com vista a ajudar os professores a lidar com situações estressantes. Promover o ajuste pessoa-trabalho, com ênfase na relação entre a pessoa e a situação de trabalho, sem considerar como variáveis isoladas afigura-se ser o caminho promissor para lidar com o burnout (MASLACH et al., 2001).

Ressalta-se que este estudo apresenta limitações, uma vez que não fornece qualquer prova de causalidade e não envolveu amostra de todos os professores do ensino superior em Moçambique. Investigações futuras baseadas em pesquisas quantitativas são necessárias para estudar o fenômeno de burnout em docentes do ensino superior e, sugerir formas de prevenção e intervenção em burnout. A realização dessas investigações poderá ser útil na identificação de fatores de trabalho adversos para a saúde e no delineamento de estratégias mais eficazes na gestão das exigências do trabalho pelos professores, o que ajudará a alargar e generalizar os resultados de burnout no trabalho.

\section{REFERÊNCIAS}

ABACAR, M. Burnout em docentes do ensino Básico em Escolas Moçambicanas e Brasileiras. 2015. $336 f$. (Tese) Doutorado em Psicologia Cognitiva. Universidade Federal de Pernambuco, Centro de Filosofia e Ciências Humanas, Pós-Graduação em Psicologia Cognitiva, Recife, 2015. 
AGUAYO, R.; VARGAS, C.; FUENTE, E. I. de la; LOZANO, L. M. A meta-analytic reliability generalization study of the Maslach Burnout Inventory. International Journal of Clinical and Health Psychology, v. 11, n. 2, p. 343361, 2011.

ALUJA, A.; BLANC, A.; GARCÍA, L. F. Dimensionality of the Maslach Burnout Inventory. In School Teachers: A Study of Several Proposals. European Journal of Psychological Assessment, v. 21, n. 1, p. 67-76, 2005.

BETORET, F. D.; ARTIGA, A. G. Barriers Perceived by Teachers at Work, Coping Strategies, Self-efficacy and Burnout. The Spanish Journal of Psychology, v. 13, n. 2, p. 637-654, 2010.

AMIMO, C. A. Are you experiencing teacher burnout? A synthesis of research reveals conventional prevention and spiritual healing. Education Research Journal, v. 2, n. 11, p. 338-344, nov. 2012.

AYDEMIR, O.; ICELLI, I. Burnout: Risk Factors. In: BÄHRER-KOHLER, S. (Ed.). Burnout for Experts: Prevention in the Context of Living and Working. Basel, Switzerland: Springer. p. 119-143, 2013.

BENETTI, R. R.; STUMM, E. M. F.; IZOLAN, F.; RAMOS, L. P.; KIRCHNER, R. M. Variáveis de burnout em profissionais de uma unidade de emergência hospitalar. Cogitare Enferm, v. 14, n. 2, p. 269-277, 2009.

BENEVIDES-PEREIRA, A. M. T. Burnout, por quê? In: A. M. T. BENEVIDES-PEREIRA. Burnout: quando o trabalho ameaça o bem-estar do trabalhador. São Paulo: Casa do Psicólogo, 2002.

BOTERO, M. L. R.; ROMERO, H. G. Burnout syndrome in professor from an academic unit of a Colombian university. Investigación y Educación en Enfermería, v. 29, n. 3, p. 427-434, 2011.

CARNEIRO, R. M. Síndrome de Burnout: um desafio para o Trabalho do Docente Universitário. 2010, 86f. (Dissertação) Mestrado Multidisciplinar em Sociedade, Tecnologia e Meio Ambiente. Pós-graduação Stricto Senso, Centro Universitário de Anápolis - UniEVANGÉLICA. Anápolis, 2010.
COSTA, B. E.; SILVA, N. L. S. Analysis of environmental factors affecting the quality of teacher's life of public schools from Umuarama. Work. v. 41, p. 3693-3700, 2012.

FERBER, B. A. Inconsequentiality: the key to understanding teacher burnout. In: VANDERBERCHE, R.; HUBERMAN, A. M. Understanding and Preventing Teacher Burnout: A Sourcebook of international research and practice. Cambridge University Press, 1999.

GARCIA, L. P.; BENEVIDES-PEREIRA, A. M. T. Investigando o Burnout em Professores Universitários. Revista Eletrônica InterAção Psy, v. 1, n. 1, p. 76-89, ago. 2003.

GIL-MONTE, P. R. El síndrome de quemarse por el trabajo (burnout) como fenómeno transcultural. Informació Psicológica, v. 91-92, p. 4-11, 2008.

GODDARD, R.; O'BRIEN, P.; GODDARD, M. Work environment predictors of beginning teacher burnout. British Educational Research Journal, v. 32, n. 6, p. 857-874, dec. 2006.

MARTINS, J. M. M. T. Burnout na Profissão Docente. 2008, 136f. (Dissertação) Mestrado em Psicologia. Faculdade de Psicologia e de Ciência de Educação, Universidade do Porto. Porto, 2008.

MASLACH, C.; JACKSON, S. E. The role of sex and family variables in burnout. Sex Roles, v. 12, n. 7/8, p. 837-851, 1985.

MASLACH, C.; JACKSON, S. E. The measurement of experienced Burnout. Journal of Occupational Behaviour, v. 2, p. 99-113, 1981.

MASLACH, C.; LEITER, M. P. Trabalho: fonte de prazer ou desgaste? Campinas, SP: Papirus, 1999.

MASLACH, C.; SCHAUFELI, W. B.; LEITER, M. P. Job burnout. Annual Review of Psychology, v. 52, p. $397-$ 422, 2001.

MILIĆEVIĆ-KALAŠIĆ, A. Burnout Examination. In: BÄHRER-KOHLER, S. (Ed). Burnout for Experts: Prevention in the Context of Living and Working. Basel, 
Switzerland: Springer, p.169-183, 2013.

OZDEMIR, Y. The Role of Classroom Management Efficacy in Predicting Teacher Burnout. International Journal of Human and Social Sciences, v. 2, n. 4, p. 256-262, 2007.

PLATSIDOU, M. Trait Emotional Intelligence of Greek Special Education Teachers in Relation to Burnout and Job Satisfaction. School Psychology International, v. 31, n. 1, p. 60-76, 2010.

SCHAUFELI, W. B.; BUUNK, B. P. Burnout: An Overview of 25 Years of Research and Theorizing. In: SCHABRACQ, M. J.; WINNUBST, J. A. M.; COOPER, C. L. (Ed.). The Handbook of Work and Health Psycholog y. [s.l]: John Wiley \& Sons, 2003.

SUDA, E. Y.; COELHO, A. T.; BERTACI, A. C., SANTOS, B. B. dos. Relação entre nível geral de saúde, dor musculoesquelética e síndrome de burnout em professores universitários. Fisioterapia e Pesquisa, São Paulo, v. 18, n. 3, p. 270-274, jul./set. 2011.

WHEELER, D. L.; VASSAR, M.; WORLEY, J. A.; BARNES, L. L. B. A Reliability Generalization Meta-Analysis of Coefficient Alfa for the Maslach Burnout Inventory. Educational and Psychological Measurement, v. 71, n. 1, p. 231-244, 2011.

YONG, Z.; YUE, Y. Causes for burnout among secondary and elementary school teachers and preventive strategies. Chinese Education and Society, v. 40, n. 5, p. 78-85, sep/oct. 2007.

Recebido em: 2017-05-29

Aceito em: 2017-11-13 